\title{
Article \\ Achievement of Room Temperature Superelasticity in Ti-Mo-Al Alloy System via Manipulation of $\omega$ Phase Stability
}

\author{
Naoki Nohira *D, Wan-Ting Chiu, Akira Umise, Masaki Tahara and Hideki Hosoda *(D) \\ Institute of Innovative Research (IIR), Tokyo Institute of Technology, 4259 Nagatsuta-cho, Midori-ku, \\ Yokohama 226-8503, Japan; chiu.w.aa@m.titech.ac.jp (W.-T.C.); umise.a.aa@m.titech.ac.jp (A.U.); \\ tahara.m.aa@m.titech.ac.jp (M.T.) \\ * Correspondence: nohira.n.aa@m.titech.ac.jp (N.N.); hosoda.h.aa@m.titech.ac.jp (H.H.)
}

\begin{abstract}
The achievement of room-temperature (RT) superelasticity in a Ti-Mo-Al ternary alloy system through the addition of a relatively high concentration of Al to manipulate the phase stability of the $\omega$ phase is realized in this study. The composition of the Ti- 6 mol\% Mo (Ti- 11.34 mass\% Mo) alloy was designated as the starting alloy, while $5 \mathrm{~mol} \% \mathrm{Al}(=2.71 \mathrm{mass} \% \mathrm{Al})$ and $10 \mathrm{~mol} \% \mathrm{Al}$ $(=5.54 \mathrm{mass} \% \mathrm{Al})$ were introduced to promote their superelastic behavior. Among the alloys, Ti-6 $\mathrm{mol} \% \mathrm{Mo}-10 \mathrm{~mol} \% \mathrm{Al}$ alloy, which was investigated for the very first time in this work, performed the best in terms of superelasticity. On the other hand, Ti- $6 \mathrm{~mol} \% \mathrm{Mo}$ and Ti- $6 \mathrm{~mol} \% \mathrm{Mo}-5 \mathrm{~mol} \% \mathrm{Al}$ alloys exhibited a shape memory effect upon heating. It is worth mentioning that in the transmission electron microscopy observation, $\omega$ phase, which appeared along with $\beta$-parent phase, was significantly suppressed as $\mathrm{Al}$ concentration was elevated up to $10 \mathrm{~mol} \%$. Therefore, the conventional difficulties of the inhibited RT superelasticity were successfully revealed by regulating the number density of the $\omega$ phase below a threshold.
\end{abstract}

Keywords: Al addition; $\omega$ phase; superelasticity; room-temperature superelasticity; shape memory effect; Ti-Mo-Al

Nohira, N.; Chiu, W.Umise, A.; Tahara, M.; Hosoda, H. Achievement of Room Temperature Superelasticity in Ti-Mo-Al Alloy

System via Manipulation of $\omega$ Phase Stability. Materials 2022, 15, 861.

https://doi.org/10.3390/

ma15030861

Academic Editor: Andrey Belyakov

Received: 4 January 2022

Accepted: 17 January 2022

Published: 23 January 2022

Publisher's Note: MDPI stays neutral with regard to jurisdictional claims in published maps and institutional affiliations.

Copyright: (c) 2022 by the authors. Licensee MDPI, Basel, Switzerland This article is an open access article distributed under the terms and conditions of the Creative Commons Attribution (CC BY) license (https:// creativecommons.org/licenses/by/ $4.0 /)$.

\section{Introduction}

Shape memory alloys (SMAs) have been extensively investigated owing to their functional properties, such as shape memory effect (SME) and superelasticity. In particular, the $\beta$-Ti-based SMAs are considered as promising candidates for the biomedical and biomaterial communities due to the aforementioned functionalities (i.e., SME and superelasticity) and good biocompatibility [1,2].

In Ti alloys, additives are classified into $\alpha$ (hcp)-stabilizing and $\beta$ (bcc)-stabilizing elements. $\mathrm{Al}$, known as a typical one, is a standard element for the calculation of Alequivalent as other $\alpha$-stabilizing elements are used, while Mo is also used for the calculation of Mo-equivalent [3]. Therefore, Ti-Mo-Al alloy, which contains $\mathrm{Al}$, a typical $\alpha$-stabilizing element and Mo, a typical $\beta$-stabilizing element, is a basic and standard model for Tialloys, and is a crucial system for fundamental research of Ti-alloys. The achievement of superelasticity in this Ti-Mo-Al basic model, which is considered as a prototype of SMA, could be a guideline for the development of various types of other $\beta$-Ti-based SMAs via the equivalent calculations. The $\beta$-type Ti-Mo-Al system was thus prepared in this study for studying its superelasticity at room temperature (RT).

The SME of $\beta$-Ti-based alloys originates from phase transformation between $\beta$ (bcc) parent and $\alpha^{\prime \prime}$ (orthorhombic) martensite phases. The Lattice deformation strain of Ti-Mo alloys between $\beta$ and $\alpha^{\prime \prime}$ phases of about $9.5 \%$ is comparable to well-known Ti-Ni alloys even when Mo was introduced to lower martensitic transformation (MT) temperature to RT [4]. Therefore, SME of Ti-Mo-based alloys has been widely investigated [5-8]. Our group also succeeded in developing RT superelasticity via MT temperature regulation by alloying $\mathrm{Zr}$ and $\mathrm{Sn}$ to Ti-3 mol\% Mo specimens [9]. Besides Ti-Mo alloys, the SME of 
Ti-Cr-Al [10] and Ti-Ta-Al [11] as well as superelasticity of Ti-Nb-Al [12-14] containing Al, have been explored.

Concerning Ti-Mo-Al systems, Sasano et al. studied SME of Ti-12Mo-3Al (mass\%) alloy [15], followed by systematic studies with various $\mathrm{Mo}$ and $\mathrm{Al}$ concentrations. It was claimed that SME was obtained in some Ti-5Mo-(6-7)Al (mol\%) and Ti-6Mo-(3-8)Al (mol\%) alloys [16]. Nevertheless, the $\mathrm{Al}$ amount for investigations of SME and MT in these studies was limited to $3-8 \mathrm{~mol} \%$ (1.5-4.5 mass $\%)$.

Ijaz et al. discovered that stress hysteresis $(\Delta \sigma)$ of superelastic Ti-Nb-Mo alloys was alleviated via $\mathrm{Sn}$ addition, which suppresses formations of the $\omega$ phase [17]. Here, $\Delta \sigma$ is the difference between the stress for inducing MT of $\beta$ phase $\left(\sigma_{\beta-\alpha^{\prime \prime}}\right)$ during loading and the stress for finishing of reverse MT $\left(\sigma_{\alpha^{\prime \prime}-\beta}\right)$ during unloading. In certain cases, reverse MT is not triggered even when applied stress is fully released in reverse MT due to a large $\Delta \sigma$, whereby superelasticity deteriorates or vanishes. To achieve superelasticity, $\Delta \sigma$ must be reduced sufficiently for the commencement of reverse MT. It is also known that Al also mitigates formations of $\omega$ phases in a similar manner as Sn [10,18-20]. Williams et al. studied the effects of $\mathrm{Al}$ on formations of the $\omega$ phase in Ti- $6 \mathrm{~mol} \%$ Mo alloys and stated that volume fraction (VF) of the $\omega$ phase was reduced with $\mathrm{Al}$ [21].

Some studies revealed the SME of the Ti-Mo-Al alloys [15,16]; however, there is still a lack of research regarding superelasticity of this system at RT. For various applications, it is critical to put both SME and superelasticity into practice in the most fundamental $\beta$-Ti-based SMAs, such as the Ti-Mo-Al in this study, since it can be a potential tool for the preparation of various types of the $\beta$-Ti-based SMAs via the Mo- and Al-equivalent calculations, as mentioned. Additionally, judging from the literature, it was concluded that by means of the already-studied $\mathrm{Al}$ composition range (i.e., less than $8 \mathrm{~mol} \%$ ) in Ti-Mo-Al alloys, it is insufficient to inhibit the formation of $\omega$ phase; consequently, superelasticity was not unveiled due to a large $\Delta \sigma$. Therefore, it is assumed that relatively high $\mathrm{Al}$ addition is necessary for the development of RT superelasticity in the Ti-Mo-Al system. Based on this assumption, RT superelasticity is expected to be imposed in Ti-Mo-Al alloys as Al concentration is beyond $8 \mathrm{~mol} \%$, which is higher than those in the literature.

In this work, to verify this hypothesis about the aforementioned $\mathrm{Al}$ addition concentration, the Ti- $6 \mathrm{~mol} \%$ Mo alloy, which allows the formation of the $\beta$ phase at RT through quenching followed by solution-treatment, was chosen as the prototype specimen. Furthermore, specific $\mathrm{Al}$ concentrations of $5 \mathrm{~mol} \%$ (i.e., within the range studied by literature) and $10 \mathrm{~mol} \%$ (i.e., out of the literature range) were designed, respectively, to certify the speculation. The correlation between deformation behaviors and formations of $\omega$ phase in Ti-Mo-Al alloys was further investigated.

\section{Materials and Methods}

High purity $\mathrm{Ti}(99.99 \%)$, Mo (99.9\%), and $\mathrm{Al}(99.99 \%)$ were used for the preparation of Ti-6Mo- $(0,5$, and 10$) \mathrm{Al}(\mathrm{mol} \%)$ alloys. Ingots of $8 \mathrm{~g}$ were fabricated by arc-melting in an $\mathrm{Ar}-1 \mathrm{~mol} \% \mathrm{H}_{2}$ atmosphere. Specimens are abbreviated as $0 \mathrm{Al}, 5 \mathrm{Al}$, and $10 \mathrm{Al}$, unless otherwise stated. Arc-melted ingots were sealed in quartz tubes under an Ar atmosphere, homogenized at $1273 \mathrm{~K}$ for $7.2 \mathrm{ks}$, quenched in iced-water, and cold-rolled into sheets. Specimens used for measurements were cut by electro-discharge machining, solutiontreated at $1273 \mathrm{~K}$ for $1.8 \mathrm{ks}$ in Ar atmosphere, followed by iced-water quenching.

For phase identification, X-ray diffraction (XRD; X'Pert-PRO-MPD, Malvern PANalytical, Malvern, UK) measurements were conducted by $\mathrm{CuK} \alpha$ radiation within $2 \theta=20-120^{\circ}$ at RT ( $295 \pm 2$ K). Scanning electron microscopy (SEM; SU5000, Hitachi High-Tech Corporation, Tokyo, Japan) and transmission electron microscopy (TEM; JEM-2100, JEOL Ltd., Tokyo, Japan) were undertaken with acceleration voltages of $15 \mathrm{kV}$ and $200 \mathrm{kV}$, respectively. Prior to TEM observations, thin foil specimens were processed by twin-jet polishing. Tensile tests were performed by an Instron universal testing machine (Autograph AG-Xplus $5 \mathrm{kN}$, Shimadzu Corporation, Kyoto, Japan) on $20 \mathrm{~mm}$ (length) $\times 2 \mathrm{~mm}$ (width) $\times 0.2 \mathrm{~mm}$ (thickness) specimens at RT. The tensile tests were conducted along the rolling direction of 
specimens at a strain rate of $8.3 \times 10^{-4} \mathrm{~s}^{-1}$ and specimens were unloaded after approximately $4 \%$ strain deformation. Those specimens did not perform superelastic recovery, were subjected to heat-treatments up to $500 \mathrm{~K} \pm 20 \mathrm{~K}$ after unloading, and shape recoveries were recorded to investigate SME.

\section{Results and Discussion}

All alloys possessed the $\beta$ phase in XRD profiles (Figure 1a), and as shown in the inset, a small peak was observed in $0 \mathrm{Al}$, which could be indexed as $\omega$ phase. Equiaxed grains of about $200 \mu \mathrm{m}$ were observed in OM images (Figure S1 in the Supplementary Materials) and no secondary phase was discerned in SEM images (Figure $1 \mathrm{~b}-\mathrm{d}$ ).
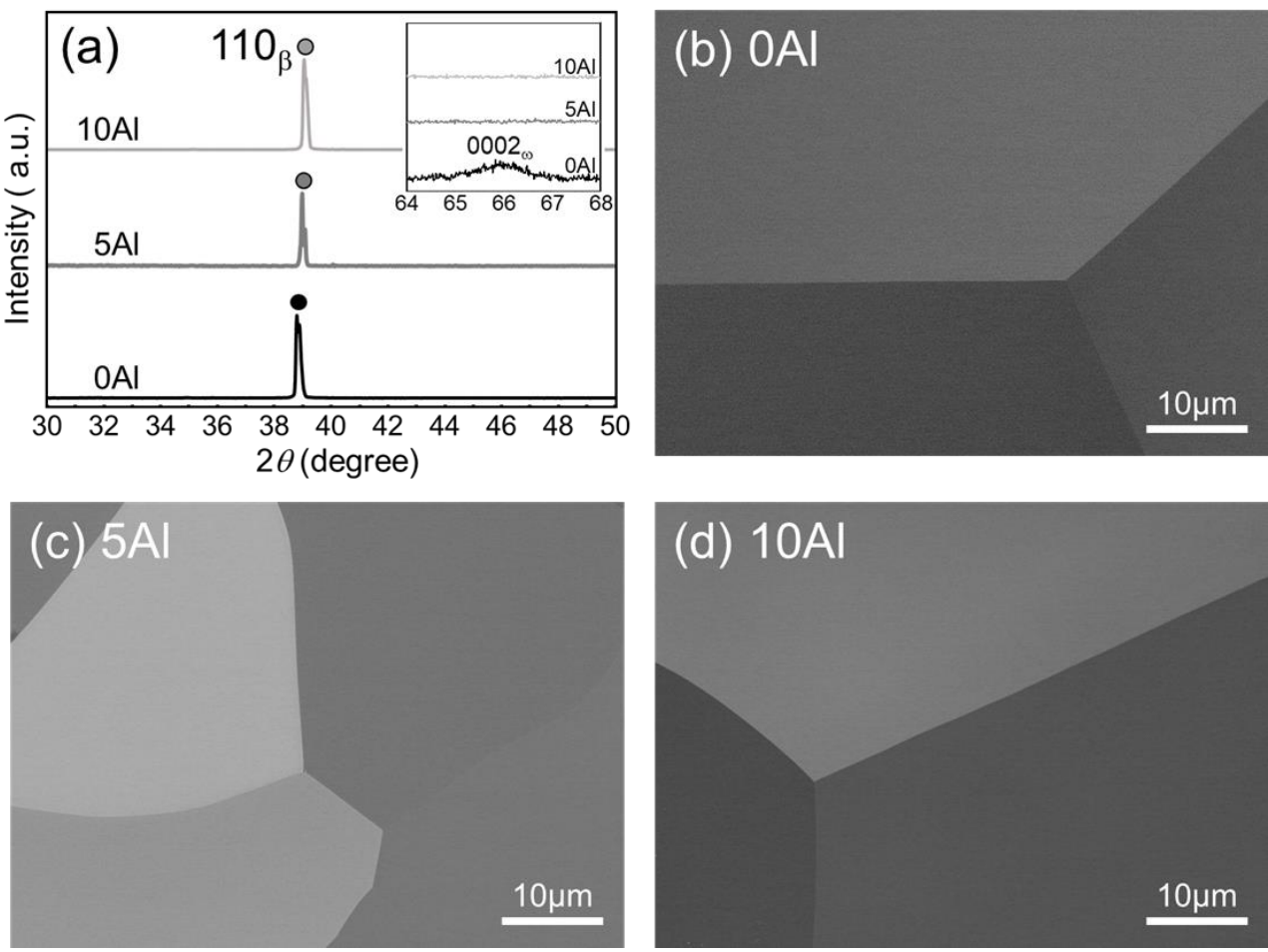

Figure 1. (a) XRD profiles of $0 \mathrm{Al}, 5 \mathrm{Al}$, and $10 \mathrm{Al}$ solution-treated alloys (magnified $\mathrm{X}$-ray diffraction patterns for three specimens from $2 \theta=64^{\circ}$ to $68^{\circ}$ are inserted in the top-right corner of (a) to reveal the diffraction peaks of $\omega$ phase). SEM images of (b) 0Al, (c) 5Al, and (d) 10Al.

Dark-field (DF) images along with corresponding selected area diffraction patterns (SADPs) from the $[110]_{\beta}$ direction are shown in Figure 2 and a fine secondary phase was identified. Besides diffraction spots of the $\beta$ phase, notwithstanding the $\mathrm{Al}$ amount, spots of the $\omega$ phase were further observed at $1 / 3$ and $2 / 3$ positions along the $<112>^{*} \beta$ direction in all SADPs. This $\omega$ phase was recognized as athermal $\omega\left(\omega_{\text {ath }}\right)$, whose area fraction (AF) and size were evaluated by Image $1.51 \mathrm{k}$. Not surprisingly, the highest AF of $12.5 \%$ possessing a major axis of approximately $6.9 \mathrm{~nm}$ and a minor axis of approximately $2.3 \mathrm{~nm}$ of $\omega_{\text {ath }}$ phase, was found in $0 \mathrm{Al}$ (Figure $2 \mathrm{a}$ ). AF of $5.9 \%$ with an average size of $3.3 \mathrm{~nm}$ and $\mathrm{AF}$ of $2.8 \%$ with an average size of $3.1 \mathrm{~nm}$ of the $\omega_{\text {ath }}$ phase were found in $5 \mathrm{Al}$ (Figure $2 \mathrm{~b}$ ) and 10Al (Figure 2c), respectively. It was thus concluded that the size and AF of the $\omega_{\text {ath }}$ phase could be diminished with Al introduction. Moreover, spots of the $\omega_{\text {ath }}$ phase in $0 \mathrm{Al}$ was observed distinctly and sharply; conversely, spots turned diffuse and faint with the Al introduction (i.e., $5 \mathrm{Al}$ and $10 \mathrm{Al}$ ), indicating that SADPs results agreed well with DF images. 

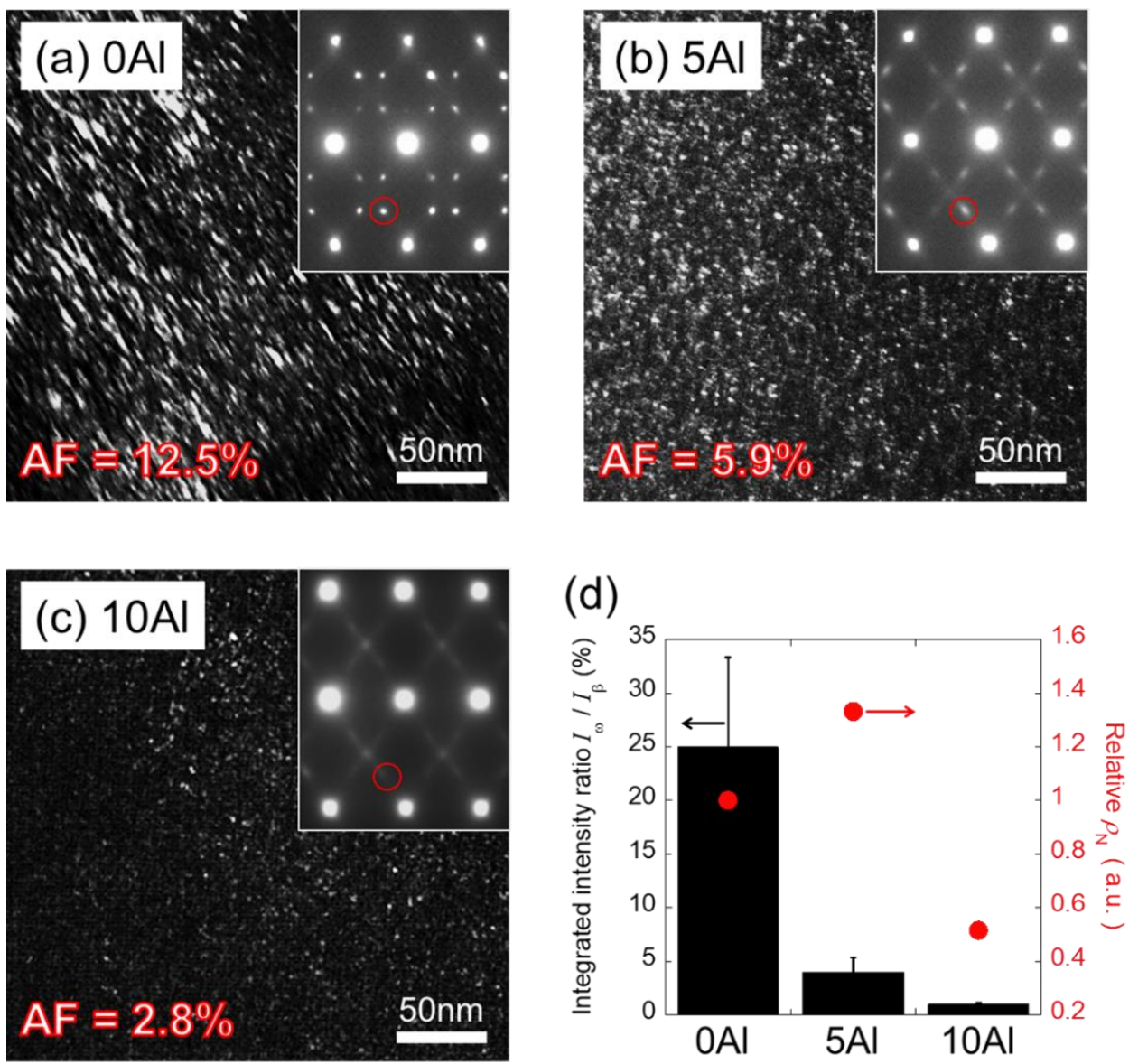

Figure 2. TEM DF images and corresponding SADPs (inserted to upper-right corner) with a $[110]_{\beta}$ zone axis of (a) 0Al, (b) 5Al, and (c) 10Al. Red circles in the insets of $(\mathbf{a}-\mathbf{c})$ indicate $\omega_{\text {ath }}$ diffractions. (d) The ratio of $I_{\omega} / I_{\beta}$ of $\omega_{\text {ath }}$ spot intensity to $\beta$ spot intensity (black bars with error bars) and relative number density $\left(\rho_{\mathrm{N}}\right)$ of $\omega_{\text {ath }}$-particles (red solid circles) for each alloy. Note that the relative $\rho_{\mathrm{N}}$ for each alloy is normalized by taking $0 \mathrm{Al}$ as a standard.

Since it is crucial to take specimen thickness into account, the total amount of $\omega_{\text {ath }}$ phase was further estimated by the $I_{\omega} / I_{\beta}$ measure of the spot intensity ratio of the $\omega_{\text {ath }}$ phase $\left(I_{\omega}\right)$ to $\beta$ phase $\left(I_{\beta}\right)$ (Figure $2 \mathrm{~d}$ ), which was calculated from the integrated intensity profiles of SADPs along $\left\langle 112>^{*} \beta\right.$ [22]. $I_{\omega} / I_{\beta}$, which is equivalent to $\mathrm{VF}$, are approximately at $25 \%, 4 \%$, and $1 \%$ for $0 \mathrm{Al}, 5 \mathrm{Al}$, and $10 \mathrm{Al}$, respectively. The subsided spot intensity of $\omega_{\text {ath }}$ phase, suggesting the diminished VF of the $\omega_{\text {ath }}$ phase originated from elevated Al. A remarkable suppression of the $\omega_{\text {ath }}$ phase was especially found in $10 \mathrm{Al}$ (i.e., the highest $\mathrm{Al}$ ) and the results are consistent with literature [20,21]. The quantification of the SADPs can be difficult; nevertheless, it is apparent that the diffraction spots of the $\omega_{\text {ath }}$ phase gradually turned weak and diffuse from $0 \mathrm{Al}$ to $10 \mathrm{Al}$.

Precipitates of the $\omega_{\text {ath }}$ phase inhibiting stress-induced martensitic transformation (SIMT), increased the stress for $\beta / \alpha$ " interface migration in a solid-solution strengtheninglike manner. Accordingly, intensified stress is reasonably speculated to correlate positively to number of pinning at the interface. First, it is assumed that $\omega_{\text {ath }}$-particles are homogeneous in size and low-composition dependent in shape. Second, $I_{\omega} / I_{\beta}$ divided by the volume of one $\omega_{\text {ath }}$-particle is proportional to the number density $\left(\rho_{\mathrm{N}}\right)$. A relative $\rho_{\mathrm{N}}$, which is normalized by serving $0 \mathrm{Al}$ as the standard, is used and shown in Figure $2 \mathrm{~d}$. The highest and lowest relative $\rho_{\mathrm{N}}$ were found of 1.3 and 0.5 for $5 \mathrm{Al}$ and $10 \mathrm{Al}$, respectively. It is thus concluded that size and $I_{\omega} / I_{\beta}$ (i.e., VF) were reduced with Al; by contrast, relative $\rho_{\mathrm{N}}$ does not show specific dependency. 
Stress-strain curves and definitions are shown in Figure 3. First, yielding stress $\left(\sigma_{\mathrm{y}}\right)$ of $0 \mathrm{Al}$ was found at $340 \mathrm{MPa}$ and the applied strain almost remained after unloading (Figure $3 a$ ). About $1 / 3$ residual strain (i.e., $0.8 \%$ ) of shape recovery took place upon heating due to SME $\left(\varepsilon_{\mathrm{sme}}\right)$. These results agreed well with Ti- $6 \mathrm{~mol} \% \mathrm{Mo}$ and Ti-11 mass $\%$ Mo (= Ti-5.81 mol\% Mo) alloys [23,24]. Additionally, Ti-11 mass\% Mo alloy possessing proximate composition to $0 \mathrm{Al}$ was reported to undergo plastic deformation mainly by twinning deformation of the $\beta$ phase $[25,26]$ and was accompanied by SIMT simultaneously in the early stage [27-30]. Moreover, Oka et al. also reported that a slight SIMT occurred in 10\% cold-rolled Ti-11 mass \% Mo alloy [31]. It is thus concluded that twinning of the $\beta$ phase is the major mechanism during deformation, while a minor amount of SIMT to the $\alpha^{\prime \prime}$ phase, which went along with it, led to shape recovery upon heating. Furthermore, since merely slight work-hardening was found in $0 \mathrm{Al}, \sigma_{\mathrm{y}}$ is considered to be equivalent to the stress for SIMT $\left(\sigma_{\text {SIMT }}\right)$. Note that slight pseudoelastic recovery during unloading was attributed to twinning pseudoelasticity caused by stress-induced martensitic variants, which is often seen in Ti-Mo-based SMAs and others.
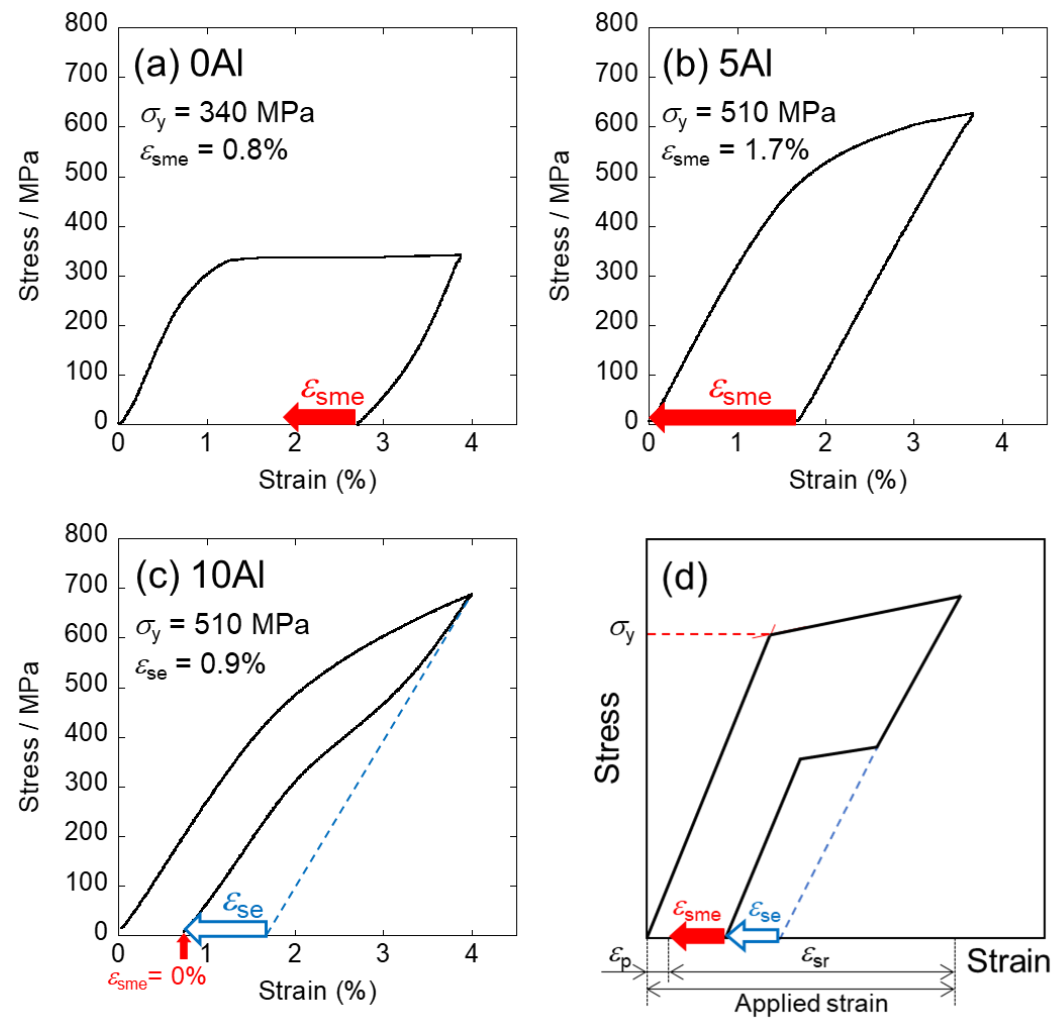

Figure 3. Stress-strain curves of (a) 0Al, (b) 5Al, and (c) 10Al. (d) Definition of each term. (Open blue arrow symbols: strain originates from superelasticity during unloading $\left(\varepsilon_{\mathrm{se}}\right)$; solid red arrow symbols: strain brought by SME upon heating $\left(\varepsilon_{\mathrm{sme}}\right) ; \varepsilon_{\mathrm{sr}}$ : strain of overall shape recovery; $\varepsilon_{\mathrm{p}}$ : strain by plastic deformation; $\sigma_{\mathrm{y}}$ : yielding stress; applied strain $=\varepsilon_{\mathrm{sr}}+\varepsilon_{\mathrm{p}}$ ).

Second, in 5Al (Figure 3b), $\sigma_{\mathrm{y}}$ was identified at approximately $510 \mathrm{MPa}$, which is higher than $0 \mathrm{Al}$. By contrast with $0 \mathrm{Al}, 5 \mathrm{Al}$ performed neither pseudoelastic nor superelastic recovery; instead, the elastic recovery was merely found during unloading. It is worth mentioning that followed by unloading, $100 \%$ shape recovery was realized upon heating performing a perfect SME. Accordingly, it is rational to infer that $\sigma_{\mathrm{y}}$ corresponds to $\sigma_{\text {SIMT }}$ and these results are supported by literature [15].

Lastly, unexplored 10Al (Figure 3c), whose $\sigma_{\mathrm{y}}$ was at approximately $510 \mathrm{MPa}$, is similar to $5 \mathrm{Al}$; nevertheless, a larger shape recovery than the amount brought by merely elastic recovery was recognized during unloading. This indicated that superelasticity was successfully revealed in $10 \mathrm{Al}$ showing a superelastic recovery strain $\varepsilon_{\text {se }}$ of $0.9 \%$ while no 
SME was found in 10Al upon heating and the residual strain remained. It is considered that the residual strain could be ascribed to slip deformation, which originates from dislocation motions, and arises along with SIMT during loading. The RT superelasticity of 10Al was practiced for the very first time in this study. Judging from the results, $\sigma_{\mathrm{y}}$ of $10 \mathrm{Al}$ is surmised to be both a critical stress for slip deformation and $\sigma_{\text {SIMT }}$. In short, $\sigma_{\mathrm{y}}$ of all specimens was accompanied with SIMT during loading in this study.

For further analysis of superelasticity of the 10Al, the cyclic loading-unloading tensile test was performed. Specimens were subjected to $1.5 \%$ stain in the first cycle followed by repeated $0.5 \%$ strain per cycle until they fractured. The stress-strain curves via the cyclic loading-unloading tensile test are shown in Figure 4a. The overall shape recovery strain $\left(\varepsilon_{\mathrm{sr}}\right)$, transformation strain of superelasticity $\left(\varepsilon_{\mathrm{se}}\right)$, and residual plastic strain $\left(\varepsilon_{\mathrm{p}}\right)$ of each cycle, which were evaluated from Figure $4 \mathrm{a}$, are plotted as a function of applied strain in Figure $4 \mathrm{~b}$. It was found that $\varepsilon_{\mathrm{sr}}$ and $\varepsilon_{\mathrm{se}}$ increased linearly up to an applied strain of $6 \%$ before decreasing. The maximum $\varepsilon_{\text {se }}$ was $2.4 \%$ at an applied strain of $6 \%$, and the maximum $\varepsilon_{\mathrm{sr}}$ reached $4.8 \%$. The obtained $\varepsilon_{\mathrm{se}}$ in this $10 \mathrm{Al}$ surpassed that of $2.3 \% \varepsilon_{\mathrm{se}}$ of the greatly investigated $\mathrm{Ti}-26 \mathrm{Nb}(\mathrm{mol} \%)$ alloy [32]. It is expected that further manipulation of the alloy composition and/or heat-treatment could develop highly practical SMAs with promoted superelastic strain. Our research group is still working on the development of other related alloys, and improvements of the $\beta$-Ti-based SMAs will be published in future.

(a)

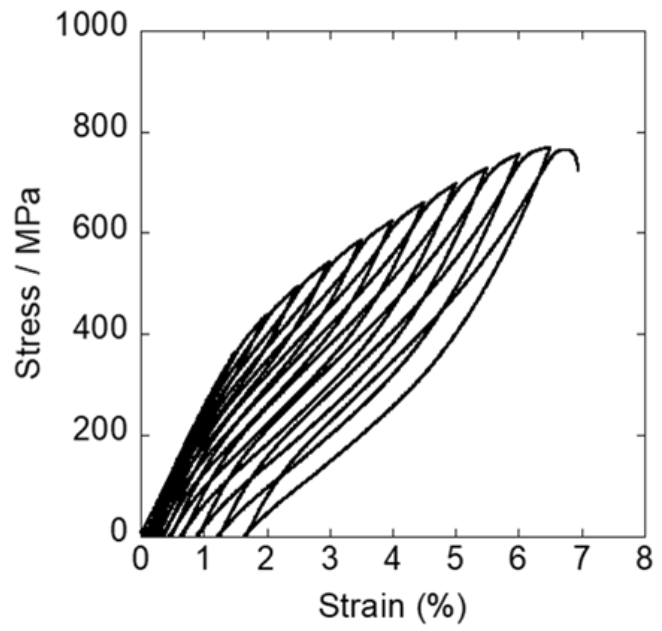

(b)

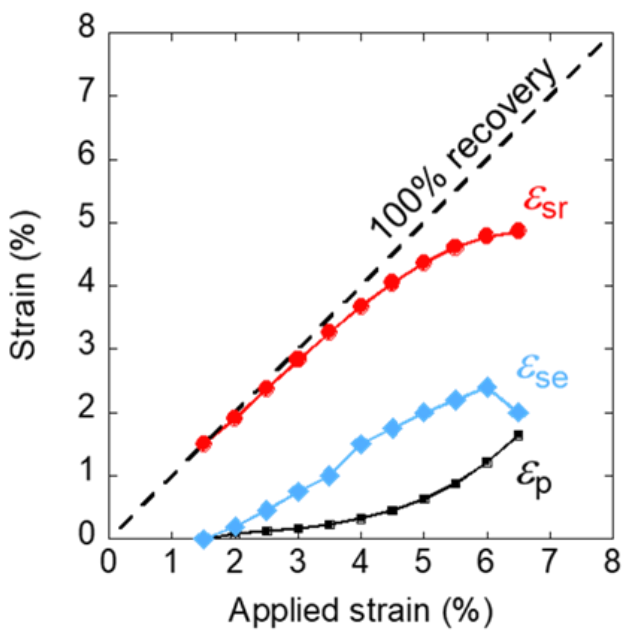

Figure 4. (a) Stress-strain curves of $10 \mathrm{Al}$ obtained from the cyclic loading-unloading tensile test. (b) Plot of various strains (overall shape recovery strain $\left(\varepsilon_{\mathrm{sr}}\right)$, transformation strain of superelasticity $\left(\varepsilon_{\mathrm{se}}\right)$, and residual plastic strain $\left.\left(\varepsilon_{\mathrm{p}}\right)\right)$ as a function of applied strain.

Given that $0 \mathrm{Al}$ and $5 \mathrm{Al}$ performed $\mathrm{SME}$ while $10 \mathrm{Al}$ exhibited superelasticity, reverse MT start temperatures $\left(A_{\mathrm{S}}\right)$ are deduced to be lower than the heating temperature of $500 \mathrm{~K}$ and RT of around $300 \mathrm{~K}$, respectively. This suggests that $A_{\mathrm{s}}$ was reduced by more than $200 \mathrm{~K}$ via $10 \% \mathrm{Al}$ addition. The reduced amount in this study agreed well with that $25-40 \mathrm{~K} / \mathrm{mol} \%$ Al claimed in literature $[12,33,34]$.

Firstly, from transformation stress and temperature points of view, generally, the $\sigma_{\beta-\alpha "}$ of SMAs follows Clausius-Clapeyron equation and increases linearly with temperature difference between MT and operation temperatures. Assuming that forward MT temperature also decreases with $\mathrm{Al}$ in the similar manner of reverse MT temperature, the lowest $\sigma_{\beta-\alpha^{\prime \prime}}$ would appear in $0 \mathrm{Al}$ and increase with $\mathrm{Al}$. However, composition dependence of $\sigma_{\beta-\alpha^{\prime \prime}}$ in this study did not show such a trend. Secondly, from a phase equilibrium point of view, while taking $A_{\mathrm{s}}$ as phase equilibrium temperature of $\beta$ phase and $\alpha^{\prime \prime}$ phase, stable phase at RT for $0 \mathrm{Al}$ and $5 \mathrm{Al}$ should be the $\alpha^{\prime \prime}$ phase. Despite the speculation, apparent phases were $\beta+\omega_{\text {ath }}$. Therefore, finally, it is rational to consider that $\beta$ phase was "quenched-in" 
by formations of the $\omega_{\text {ath }}$ phase. According to the inferences, it is necessary to take the suppression of SIMT by the $\omega_{\text {ath }}$ phase into account. It is expected that suppression of phase transformation increases with the $\omega_{\text {ath }}$ phase amount resulting in high $\sigma_{\text {SIMT }}$.

A small amount of the $\omega_{\text {ath }}$ phase (i.e., small $I_{\omega} / I_{\beta}$ ) but high $\rho_{N}$ was found in $5 \mathrm{Al}$, whose $\sigma_{\beta-\alpha^{\prime \prime}}$ at $510 \mathrm{MPa}$ was $170 \mathrm{MPa}$ higher than $340 \mathrm{MPa}$ of $0 \mathrm{Al}$, indicating that suppression of SIMT greatly depends on $\rho_{\mathrm{N}}$. Not surprisingly, $10 \mathrm{Al}$ possessing both a small amount and low $\rho_{\mathrm{N}}$ of the $\omega_{\text {ath }}$ phase performed superelasticity. This could be attributed to the least suppressed SIMT leading to a limited increment of $\sigma_{\beta-\alpha^{\prime \prime}}$. It was concluded that to achieve RT superelasticity, it is crucial to suppress both the amount and $\rho_{\mathrm{N}}$ of the $\omega_{\text {ath }}$ phase. Based on our results, keeping $\rho_{\mathrm{N}}$ below a threshold is especially an effective strategy. Therefore, introducing additive elements which sufficiently suppress the $\omega_{\text {ath }}$ phase could be practicable; moreover, as mentioned previously, $A_{\mathrm{s}}$, which is less affected by $\omega_{\text {ath }}$ phase than $M_{\mathrm{s}}$, is also a critical factor.

Based on the results, the effect of $\mathrm{Al}$ on $\sigma_{\beta-\alpha^{\prime \prime}}$ and $\sigma_{\alpha^{\prime \prime}-\beta}$ are summarized and illustrated in Figure 5 and Table S1. In Figure $5 \mathrm{a}, \sigma_{\beta-\alpha^{\prime \prime}}$ deviates from the linear relationship showing an inflection point as the composition goes from high $\mathrm{Al}$ (i.e., 10Al) to low $\mathrm{Al}$ (i.e., $5 \mathrm{Al}$ ), which contains high $\rho_{\mathrm{N}}$ and an increment of $\sigma_{\beta-\alpha^{\prime \prime}}$ was thus imposed. On the other hand, during unloading, the effect from the $\omega_{\text {ath }}$ phase, which suppressed reverse SIMT, is limited; therefore, a linear relationship was constructed (Figure $5 b$ ). A summary of stress hysteresis $(\Delta \sigma)$ based on the superimposing of loading (Figure 5a) and unloading (Figure $5 \mathrm{~b}$ ) results is illustrated in Figure 5c. Obviously, significant reduction of $\Delta \sigma$ achieved by $10 \mathrm{Al}$, was found at approximately $180 \mathrm{MPa}$ (Figure 3c).

The phase constituents and phase transformations are summarized in Table 1. There are two possible reasons for achieving RT superelasticity via $10 \mathrm{~mol} \% \mathrm{Al}$ addition. First, the transformation temperature of $10 \mathrm{Al}$ was lower than $5 \mathrm{Al}$ and the stable phase at RT thus turned into $\beta$ phase. Second, both the amount and $\rho_{\mathrm{N}}$ of the $\omega_{\text {ath }}$ phase were greatly suppressed; accordingly, $\Delta \sigma$, which was mitigated to about $180 \mathrm{MPa}$, enabled reverse SIMT at RT. In brief, for obtaining RT superelasticity, an $\mathrm{Al}$ amount up to $10 \mathrm{~mol} \%$ is a crucial prerequisite.

In $5 \mathrm{Al}$, by contrast, despite a small amount of the $\omega_{\text {ath }}$ phase, $\Delta \sigma$ was deteriorated by high $\rho_{\mathrm{N}}$. Whether superelasticity could be imposed by simply introducing Mo for reducing $A_{\mathrm{S}}$ below $\mathrm{RT}$ at $5 \mathrm{~mol} \% \mathrm{Al}$ or not, is considered by making the following presumptions. According to the results, it is known that $\sigma_{\beta-\alpha^{\prime \prime}}$ of $5 \mathrm{Al}$ is $510 \mathrm{MPa}$ and $\Delta \sigma$ at around $700 \mathrm{MPa}$ is also estimated (Figure $3 \mathrm{~b}$ ). It could also be inferred that, like $10 \mathrm{Al}, \beta$ phase would be stable at RT as $A_{\mathrm{s}}$ is $100 \mathrm{~K}$ lower than current $A_{\mathrm{s}}$. According to literature concerning metastable $\beta$-Ti alloys, the slope of the Clausius-Clapeyron relation $\left(d \sigma_{\beta-\alpha^{\prime \prime}} / d T\right)$ is $3-5 \mathrm{MPa} / \mathrm{K}$ [35-37]. By considering the minimum of $3 \mathrm{MPa} / \mathrm{K}$, it is deduced that transformation temperature of $100 \mathrm{~K}$ is reduced while $\sigma_{\beta-\alpha^{\prime \prime}}$ of $300 \mathrm{MPa}$ is increased. Consequently, $\sigma_{\beta-\alpha^{\prime \prime}}$ would be at approximately $810 \mathrm{MPa}$ via Mo introduction.

Generally, the $\sigma_{\mathrm{y}}$ of solution-treated Ti-alloys is less than $600 \mathrm{MPa}$, while the average critical stress for slip ( $\left.\sigma_{\mathrm{CSS}}\right)$ of Ti-Mo-Sn-Zr alloys exhibiting RT superelasticity is $634 \mathrm{MPa}$ [9], and Ti-20Zr-12Nb-2Sn alloy was found in a relatively high $\sigma_{\mathrm{CSS}}$ of approximately $800 \mathrm{MPa}$ until very recently [38]. Therefore, MT is not induced in alloys possessing such a high $\sigma_{\beta-\alpha^{\prime \prime}}$; instead, only plastic deformation takes place. Specifically, both SME and superelasticity disappear. This thus explains well the vanishing superelasticity by merely regulating MT temperature via Mo addition without taking the $\omega_{\text {ath }}$ phase into consideration. Additionally, since many Ti-based superelastic alloys performed $\Delta \sigma$ less than $200 \mathrm{MPa}[9,17]$, suppressing $\Delta \sigma$ to less than $200 \mathrm{MPa}$ for revealing superelasticity is required; hence, $\mathrm{Al}$ addition up to $10 \mathrm{~mol} \%$, which possessed $\Delta \sigma$ of $180 \mathrm{MPa}$, is a crucial prerequisite. 
(a)

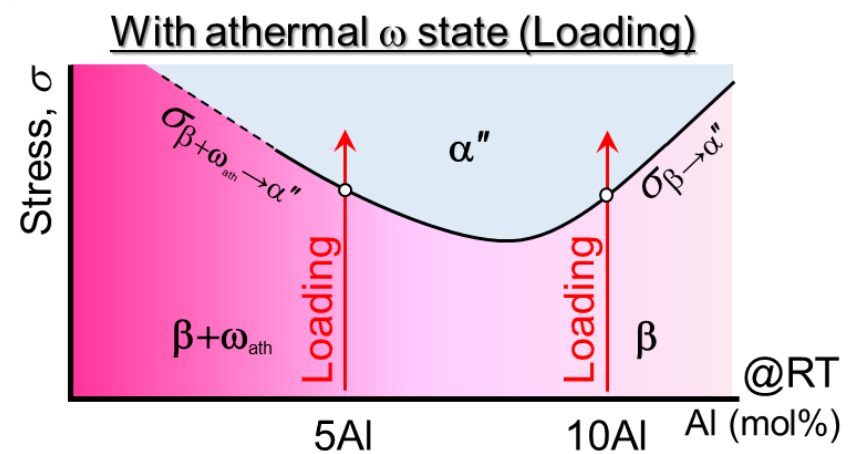

(b)

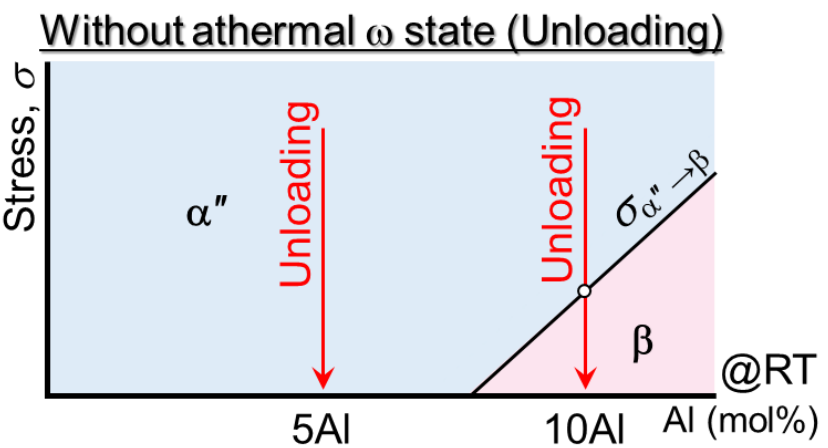

(c)

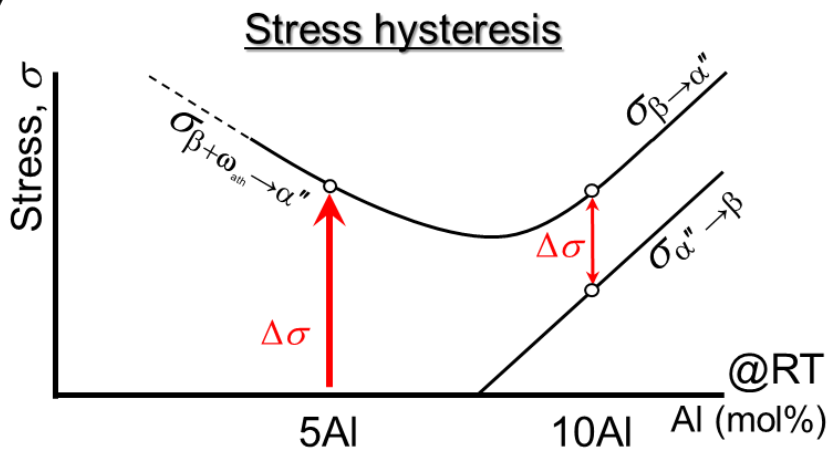

Figure 5. Illustrations of the effect of $\mathrm{Al}$ concentration on (a) phase stability during loading $\mathrm{w} / \omega_{\text {ath }}$ phase, (b) phase stability during unloading w/o $\omega_{\text {ath }}$ phase, and (c) stress hysteresis of Ti-6Mo-Al alloys.

Table 1. The phase constituents and phase transformations at (a) quenched-in, (b) intrinsically stable $\left(\mathrm{w} / \mathrm{o} \omega_{\text {ath }}\right.$ phase), (c) loading $\mathrm{w} / \omega_{\text {ath }}$ phase, and (d) unloading $\mathrm{w} / \mathrm{o} \omega_{\text {ath }}$ phase states.

\begin{tabular}{ccccc}
\hline Alloy & (a) Quenched-In State & (b) Phase Stability & (c) Loading & (d) After Unloading \\
\hline $0 \mathrm{Al}$ & $\beta+\omega_{\text {ath }}$ & $\alpha^{\prime \prime}$ & $\beta+\omega_{\text {ath }} \rightarrow \beta_{\text {twin }}\left(+\alpha^{\prime \prime}\right)$ & $\beta_{\text {twin }}\left(+\alpha^{\prime \prime}\right)$ \\
$5 \mathrm{Al}$ & $\beta+\omega_{\text {ath }}$ & $\alpha^{\prime \prime}$ & $\beta+\omega_{\text {ath }} \rightarrow \alpha^{\prime \prime}$ & $\alpha^{\prime \prime}$ \\
$10 \mathrm{Al}$ & $\beta\left(+\omega_{\text {ath }}\right)$ & $\beta$ & $\beta \rightarrow \alpha^{\prime \prime}$ & $\beta$ \\
\hline
\end{tabular}

\section{Conclusions}

In summary, size, amount, and $\rho_{\mathrm{N}}$ of the $\omega_{\text {ath }}$ phase were reduced to such an extent that the $\Delta \sigma$ in Ti-Mo-Al alloys was as low as $180 \mathrm{MPa}$ by increasing $\mathrm{Al}$ to $10 \mathrm{~mol} \%$, which was beyond already studied samples and has not been explored. Meanwhile, RT superelasticity could be realized by lowering its $A_{\mathrm{s}}$ below RT. Based on equivalent calculations, additions greater than $6 \mathrm{~mol} \%$ Mo-equivalent and $10 \mathrm{~mol} \%$ Al-equivalent would 
perform RT superelasticity. The Mo-equivalent corresponds to $8.4 \mathrm{~mol} \% \mathrm{Cr}, 5.5 \mathrm{~mol} \% \mathrm{Co}$, and $3.9 \mathrm{~mol} \%$ Fe of typical $\beta$-stabilizing elements. Via precise composition manipulation, advancing unexplored RT superelastic alloys is foreseen.

Supplementary Materials: The following supporting information can be downloaded at: https: / / www.mdpi.com/article/10.3390/ma15030861/s1, Figure S1: OM images of (a) 0Al, (b) 5Al, and (c) 10Al. Table S1: Summary of the (a) area fraction (AF) of $\omega_{\text {ath }}$ phase, (b) diameter of $\omega_{\text {ath }}$ phase, (c) intensity ratio of $\omega_{\text {ath }}$ phase to $\beta$ phase $I_{\omega} / I_{\beta}$, and (d) relative number density $\left(\rho_{N}\right)$.

Author Contributions: Conceptualization, N.N. and H.H.; Data curation, N.N. and W.-T.C.; Formal analysis, N.N. and W.-T.C.; Funding acquisition, M.T. and H.H.; Investigation, N.N. and W.-T.C.; Methodology, N.N.; Project administration, H.H.; Resources, M.T. and H.H.; Supervision, W.-T.C., A.U., M.T. and H.H.; Validation, W.-T.C., A.U., M.T. and H.H.; Visualization, N.N. and W.-T.C.; Writing—original draft, N.N.; Writing—review and editing, W.-T.C. and H.H. All authors have read and agreed to the published version of the manuscript.

Funding: This work is supported by the Japan Society for the Promotion of Science (JSPS) (KAKENHI 19H02417 and KAKENHI 20K20544).

Institutional Review Board Statement: Not applicable.

Informed Consent Statement: Not applicable.

Data Availability Statement: All data contained within the article.

Acknowledgments: We wish to thank Yoshiaki Oshita and Keigo Kimura for experimental help.

Conflicts of Interest: The authors declare no conflict of interest.

\section{References}

1. Biesiekierski, A.; Wang, J.; Abdel-Hady Gepreel, M.; Wen, C. A new look at biomedical ti-based shape memory alloys. Acta Biomater. 2012, 8, 1661-1669. [CrossRef] [PubMed]

2. Li, Y.; Yang, C.; Zhao, H.; Qu, S.; Li, X.; Li, Y. New developments of Ti-based alloys for biomedical applications. Materials 2014, 7, 1709-1800. [CrossRef] [PubMed]

3. Boyer, R.; Welsch, G.; Collings, E.W. Materials Properties Handbook: Titanium Alloys; ASM International: Materials Park, OH, USA, 1994.

4. $\quad$ Davis, R.; Flower, H.M.; West, D.R.F. Martensitic Transformations in Ti-Mo Alloys. J. Mater. Sci. 1979, 14, 712-722. [CrossRef]

5. Maeshima, T.; Nishida, M. Shape memory properties of biomedical Ti-Mo-Ag and Ti-Mo-Sn alloys. Mater. Trans. 2004, 45, 1096-1100. [CrossRef]

6. Maeshima, T.; Nishida, M. Shape memory and mechanical properties of biomedical Ti-Sc-Mo alloys. Mater. Trans. 2004, 45, 1101-1105. [CrossRef]

7. Kim, H.Y.; Ohmatsu, Y.; Kim, J.I.; Hosoda, H.; Miyazaki, S. Mechanical properties and shape memory behavior of Ti-Mo-Ga alloys. Mater. Trans. 2004, 45, 1090-1095. [CrossRef]

8. Maeshima, T.; Ushimaru, S.; Yamauchi, K.; Nishida, M. Effect of heat treatment on shape memory effect and superelasticity in Ti-Mo-Sn alloys. Mater. Sci. Eng. A 2006, 438-440, 844-847. [CrossRef]

9. Endoh, K.; Tahara, M.; Inamura, T.; Hosoda, H. Effect of Sn and Zr content on superelastic properties of Ti-Mo-Sn-Zr biomedical alloys. Mater. Sci. Eng. A 2017, 704, 72-76. [CrossRef]

10. Sugano, D.; Ikeda, M. The effect of aluminum content on phase constitution and heat treatment behavior of Ti-Cr-Al alloys for healthcare application. Mater. Sci. Eng. C 2005, 25, 377-381. [CrossRef]

11. Buenconsejo, P.J.S.; Kim, H.Y.; Miyazaki, S. Novel $\beta$-TiTaAl alloys with excellent cold workability and a stable high-temperature shape memory effect. Scr. Mater. 2011, 64, 1114-1117. [CrossRef]

12. Fukui, Y.; Inamura, T.; Hosoda, H.; Wakashima, K.; Miyazaki, S. Mechanical properties of a Ti-Nb-Al shape memory alloy. Mater. Trans. 2004, 45, 1077-1082. [CrossRef]

13. Hosoda, H.; Kinoshita, Y.; Fukui, Y.; Inamura, T.; Wakashima, K.; Kim, H.Y.; Miyazaki, S. Effects of short time heat treatment on superelastic properties of a Ti-Nb-Al biomedical shape memory alloy. Mater. Sci. Eng. A 2006, 438-440, 870-874. [CrossRef]

14. Farooq, M.U.; Khalid, F.A.; Zaigham, H.; Abidi, I.H. Superelastic behaviour of Ti-Nb-Al ternary shape memory alloys for biomedical applications. Mater. Lett. 2014, 121, 58-61. [CrossRef]

15. Sasano, H.; Suzuki, T. Shape Memory Effect in Ti-Mo-Al Alloys. In Proceedings of the 5th International Conference on Titanium, Munich, Germany, 10-14 September 1984; pp. 1667-1674.

16. Hosoda, H.; Hosoda, N.; Miyazaki, S. Mechanical properties of Ti-Mo-Al biomedical shape memory alloys. Trans. Mater. Res. Soc. Japan 2001, 26, 243-246. 
17. Ijaz, M.F.; Kim, H.Y.; Hosoda, H.; Miyazaki, S. Effect of Sn addition on stress hysteresis and superelastic properties of a Ti-15Nb-3Mo alloy. Scr. Mater. 2014, 72-73, 29-32. [CrossRef]

18. Ishiyama, S.; Hanada, S.; Izumi, O. Effect of $\mathrm{Zr}$, Sn and $\mathrm{Al}$ additions on deformation mode and beta phase stability of metastable beta Ti alloys. ISIJ Int. 1991, 31, 807-813. [CrossRef]

19. Ohyama, H.; Nishimura, T. Effects of alloying elements on deformation mode in Ti-V based $\beta$ titanium alloy system. ISIJ Int. 1995, 35, 927-936. [CrossRef]

20. Wang, W.; Zhang, X.; Sun, J. Phase stability and tensile behavior of metastable $\beta$ Ti-V-Fe and Ti-V-Fe-Al alloys. Mater. Charact. 2018, 142, 398-405. [CrossRef]

21. Williams, J.C.; Hickman, B.S.; Leslie, D.H. The effect of ternary additions on the decompositon of metastable beta-phase titanium alloys. Metall. Trans. 1971, 2, 477-484. [CrossRef]

22. Pang, E.L.; Pickering, E.J.; Baik, S.I.; Seidman, D.N.; Jones, N.G. The effect of zirconium on the omega phase in Ti-24Nb-[0-8]Zr (at.\%) alloys. Acta Mater. 2018, 153, 62-70. [CrossRef]

23. Matsugi, K.; Kishimoto, H.; Yamakawa, D.; Xu, Z.-F.; Choi, Y.-B. Compositional optimization of $\beta$ type titanium alloys with shape memory ability and their characteristics. Mater. Trans. 2015, 56, 1747-1755. [CrossRef]

24. Wang, C.H.; Liu, M.; Hu, P.F.; Peng, J.C.; Wang, J.A.; Ren, Z.M.; Cao, G.H. The effects of $\alpha^{\prime \prime}$ and $\omega$ phases on the superelasticity and shape memory effect of binary Ti-Mo alloys. J. Alloys Compd. 2017, 720, 488-496. [CrossRef]

25. Hanada, S.; Izumi, O. Transmission electron microscopic observations of mechanical twinning in metastable beta titanium alloys. Metall. Trans. A 1986, 17, 1409-1420. [CrossRef]

26. Takemoto, Y.; Shimizu, I.; Sakakibara, A.; Senuma, T. Change of elastic behavior in binary $\beta$-type Ti alloys with deformation. J. Japan Inst. Met. 2006, 70, 110-113. [CrossRef]

27. Sun, F.; Zhang, J.Y.; Marteleur, M.; Gloriant, T.; Vermaut, P.; Laillé, D.; Castany, P.; Curfs, C.; Jacques, P.J.; Prima, F. Investigation of early stage deformation mechanisms in a metastable $\beta$ titanium alloy showing combined twinning-induced plasticity and transformation-induced plasticity effects. Acta Mater. 2013, 61, 6406-6417. [CrossRef]

28. Zhang, J.Y.; Li, J.S.; Chen, Z.; Meng, Q.K.; Sun, F.; Shen, B.L. Microstructural evolution of a ductile metastable $\beta$ titanium alloy with combined TRIP/TWIP effects. J. Alloys Compd. 2017, 699, 775-782. [CrossRef]

29. Mantri, S.A.; Sun, F.; Choudhuri, D.; Alam, T.; Gwalani, B.; Prima, F.; Banerjee, R. Deformation induced hierarchical twinning coupled with omega transformation in a metastable $\beta$-Ti alloy. Sci. Rep. 2019, 9, 1334. [CrossRef]

30. Im, Y.D.; Lee, Y.K. Effects of Mo concentration on recrystallization texture, deformation mechanism and mechanical properties of Ti-Mo binary alloys. J. Alloys Compd. 2020, 821, 153508. [CrossRef]

31. Oka, M.; Taniguchi, Y. Stress-induced products in meta-stable beta Ti-Mo and Ti-V alloys. J. Japan Inst. Met. 1978, 42, 814-820. [CrossRef]

32. Kim, H.Y.; Ikehara, Y.; Kim, J.I.; Hosoda, H.; Miyazaki, S. Martensitic transformation, shape memory effect and superelasticity of Ti-Nb binary alloys. Acta Mater. 2006, 54, 2419-2429. [CrossRef]

33. Buenconsejo, P.J.S.; Kim, H.Y.; Miyazaki, S. Effect of ternary alloying elements on the shape memory behavior of Ti-Ta alloys. Acta Mater. 2009, 57, 2509-2515. [CrossRef]

34. Kim, H.Y.; Nakai, K.; Fu, J.; Miyazaki, S. Effect of Al addition on superelastic properties of Ti-Zr-Nb-based alloys. Funct. Mater. Lett. 2017, 10, 1740002. [CrossRef]

35. Kim, H.Y.; Hashimoto, S.; Kim, J.I.; Hosoda, H.; Miyazaki, S. Mechanical properties and shape memory behavior of Ti-Nb alloys. Mater. Trans. 2004, 45, 2443-2448. [CrossRef]

36. Kim, J.I.; Kim, H.Y.; Inamura, T.; Hosoda, H.; Miyazaki, S. Shape memory characteristics of Ti-22Nb-(2-8)Zr(at.\%) biomedical alloys. Mater. Sci. Eng. A 2005, 403, 334-339. [CrossRef]

37. Kim, H.Y.; Hashimoto, S.; Kim, J.I.; Inamura, T.; Hosoda, H.; Miyazaki, S. Effect of Ta addition on shape memory behavior of Ti-22Nb alloy. Mater. Sci. Eng. A 2006, 417, 120-128. [CrossRef]

38. Gao, J.J.; Thibon, I.; Castany, P.; Gloriant, T. Effect of grain size on the recovery strain in a new Ti-20Zr-12Nb-2Sn superelastic alloy. Mater. Sci. Eng. A 2020, 793, 139878. [CrossRef] 